\title{
Perspectivas sobre desenvolvimento democrático e qualidade da democracia: Brasil e América Latina
}

\author{
Maria Celina D’Araujo \\ Doutora em Ciência Política (IUPERJ) \\ Professora da Pontifícia Universidade Católica do Rio de Janeiro \\ Rio de Janeiro, Brasil \\ mariacelina@daraujo.net
}

GUILHERME LEITE RIBEIRO

Mestrando em Ciências Sociais (PUC-RJ)

Rio de Janeiro, Brasil

guiribeiro_12@hotmail.com

\begin{abstract}
Resumo $\mathrm{O}$ artigo apresenta um quadro geral do estado da democracia no Brasil e em outros 17 países da América Latina e está dividido em duas partes. Na primeira, mostra-se que a democracia política alcançou patamares inéditos nesses países e que melhorias substanciais nos indicadores socioeconômicos são visíveis em praticamente todos eles. Explicita-se ainda que a emergência de lideranças personalistas impacta negativamente os índices de desenvolvimento democrático. $\mathrm{Na}$ segunda parte, enfocamos o caso brasileiro, que se destaca também por dados positivos na área social e que tem aprovado uma série de medidas com vistas a aperfeiçoar controles eleitorais e de governo. $\mathrm{O}$ artigo argumenta que o processo de democratização e de liberalização política nesses países é inequívoco, mas nem sempre linear e progressivo, e que o desrespeito pela vida bem como a persistente desigualdade estrutural parecem demandar novas formas de pensar as práticas democráticas na América Latina.
\end{abstract}

Palavras-chave: qualidade da democracia; América Latina; Brasil; desigualdades; partidos políticos.

\section{Apresentação}

$\mathrm{Q}$ UANDO ANAlisamos o processo de democratização do Brasil e dos demais países da América Latina, não podemos deixar de lado as longas experiências autoritárias regionais, intercaladas por interregnos de curtas experiências democráticas, bem como a longa história de instabilidade e de violência política. Nos últimos trinta anos, a região experimenta, de maneira inédita, no que toca à sua durabilidade, a relativa estabilidade das instituições políticas democráticas, fenômeno potencializado pela ampliação de mecanismos fiscalizadores dos poderes constituídos - ainda que careçam de maior atenção por parte da sociedade e dos próprios governantes (Moisés, 2014).

O presente artigo apresenta um quadro geral do estado da democracia em 18 países da América Latina. Argumentamos que o processo de democratização e de liberalização política na região é inequívoco, 
embora nem sempre linear e progressivo, e que o desrespeito pela vida e a desigualdade estrutural parecem demandar novas formas de pensar as práticas democráticas na região.

Inicialmente chamamos atenção para dois fatos contrastantes. Em primeiro lugar, os indicadores positivos na área política são contrabalançados pela emergência de lideranças personalistas apoiadas por mudanças eleitorais que visam à reeleição de presidentes (Corrales e Pendolfi, 2014), comprometendo a rotatividade no poder e impactando negativamente os indicadores de desenvolvimento da democracia. Em segundo lugar, verificam-se na região indicadores positivos também na área econômica e social, embora continue a ser o continente mais desigual e mais violento do mundo. Estas contradições desafiam o entendimento sobre a qualidade da democracia em suas várias dimensões. $\mathrm{O}$ artigo caminha na direção de mapear os avanços na democracia na região recorrendo a uma variedade de recursos de que dispomos hoje para avaliar práticas político-governativas, eleitorais e de accountability, todas de fundamental importância para o desempenho dos governos democráticos no que toca aos princípios fundamentais da cidadania.

Para efeitos teóricos estamos tomando como ponto de partida o conceito de Morlino (2011 e 2013) sobre qualidade da democracia. Para este autor uma democracia de qualidade significa a existência de uma estrutura institucional estável que torne possível aos cidadãos, associações e comunidades o usufruto da liberdade e da igualdade por meio do funcionamento legítimo de suas instituições. Isso implica estudar, segundo Morlino, as ações dos governos democráticos a partir de seus conteúdos, procedimentos e resultados nos campos do Estado de direito, da participação política, da competição e da transparência eleitoral, da liberdade, da responsividade, da solidariedade e da igualdade. Existem outras variantes possíveis para pensar o conceito bem como algumas divergências sobre sua eficácia ${ }^{1}$. De toda forma, esse debate ganha força, e o termo "qualidade da democracia" continua sendo adequado para pensar as democracias emergentes e, especialmente, as democracias estáveis (Barreda, 2011).

Levando em conta essa definição, será analisada também a maneira como o debate sobre a qualidade da democracia insere-se no contexto brasileiro, pontuando novas formas de aprofundar a discussão. Para tanto, faremos breve comparação com indicadores de outros países. Priorizamos os vizinhos latino-americanos pelo fato de apresentarem características econômicas e sociopolíticas mais próximas das nossas, sobretudo no que concerne às transições políticas após períodos de ditaduras militares ou de guerras civis.

Situaremos o Brasil e outros 17 países em diferentes aspectos, desde os que se referem ao apoio das sociedades à democracia até aqueles que refletem o desenvolvimento democrático em níveis específicos. Demonstraremos que o avanço da qualidade da democracia não é um fenômeno linear e progressivo na região. Verifica-se também que no caso do Brasil, e não apenas neste país, déficits expressivos são notados nas esferas da accountability vertical e horizontal ${ }^{2}$.

Sobre os 18 países escolhidos, dispomos de pesquisas consistentes e contínuas acerca de variáveis idênticas ao longo de pelo menos mais de uma década. Esses países são: Argentina, Bolívia, Brasil, Chile, Colômbia, Costa Rica, El Salvador, Equador, Guatemala, Honduras, México, Nicarágua, Panamá, Paraguai, Peru, República Dominicana, Uruguai e Venezuela ${ }^{3}$.

Vários deles fazem parte do grupo identificado pelo efeito político da "onda rosa", ou seja, pela eleição de governos populares a partir de fins do século $\mathrm{XX}$, após a crise do modelo desenvolvimentista e de experiências, mais ou menos liberalizantes, em torno das reformas econômicas e administrativas dos anos 1980/90. Da mesma maneira, vários passaram nos últimos anos por contestações populares, de múltiplas naturezas, como Argentina, Bolívia, Brasil, Equador, Peru eVenezuela. São manifestações que atestam o vigor e os limites da competição política, algumas vezes entendidas como "contrarrevolução" (Silva, 2014).

Na América Latina, golpes militares ou interrupções violentas de governo estão desautorizadas pelas constituições nacionais e pelos organismos internacionais a exemplo da OEA, do MERCOSUL e da UNASUL. Renúncias e afastamentos abruptos foram verificados em alguns países, mas em nenhum deles surgiram ditaduras militares ou governos completamente formados à margem da Constituição (Pérez-Liñán, 2014; Pion-Berlin e Trinkunas, 2010). Em vários deles, as Forças Armadas têm sido chamadas para endossar saídas populares exercendo o que Pion-Berlin e Trinkunas (2010) chamam de poder tribunício. Ou seja, a região experimenta uma estabilidade política formal jamais observada desde que se tornou um conjunto de países independentes, embora conviva com índices ímpares em termos de violência interpessoal ${ }^{4}$.

1 Há uma vasta literatura sobre o tema na América Latina, como em Barreda (2011), Hagopian (2005) e Levine e Molina (2007). Para um resumo acerca do debate conceitual, ver Gugliano (2013).

2 Os conceitos de accountability vertical e horizontal foram paradigmaticamente definidos por O'Donnell (1998).

3 Os dados sobre estes países são extraídos das seguintes fontes: The Economist, Latinobarómetro, Freedom House, IDD Lat e Idea, entre outros. 4 Sobre a estabilidade política na região, ver D’Araujo (2010), e sobre violência, ver o Relatório Mundial sobre a Prevenção da Violência (2014), disponível em <http://www.who.int/violence_injury_prevention/violence/status_report/2014/en/> (último acesso: 07/06/2015). 
Quadro 1.1 - Índice de democracia política em 18 países da América Latina

\begin{tabular}{|c|c|c|c|c|c|c|c|c|c|c|c|c|c|c|}
\hline \multirow[b]{2}{*}{ País } & \multicolumn{2}{|c|}{$\begin{array}{l}\text { Posição no } \\
\text { ranking } \\
\text { (167 países) }\end{array}$} & \multicolumn{2}{|c|}{ Pontuação final } & \multicolumn{2}{|c|}{$\begin{array}{l}\text { Processo } \\
\text { eleitoral e } \\
\text { pluralismo }\end{array}$} & \multicolumn{2}{|c|}{$\begin{array}{c}\text { Funcionamento } \\
\text { do governo }\end{array}$} & \multicolumn{2}{|c|}{$\begin{array}{l}\text { Participação } \\
\text { política }\end{array}$} & \multicolumn{2}{|c|}{ Cultura política } & \multicolumn{2}{|c|}{ Liberdades civi } \\
\hline & 2006 & 2014 & 2006 & 2014 & 2006 & 2014 & 2006 & 2014 & 2006 & 2014 & 2006 & 2014 & 2006 & 2014 \\
\hline Uruguai & $27^{\circ}$ & $17^{\circ}$ & 7.96 & 8.17 & 10.0 & 10.0 & 8.21 & 8.93 & 5.00 & 4.44 & 6.88 & 7.50 & 9.71 & 10.0 \\
\hline Costa Rica & $25^{\circ}$ & $24^{\circ}$ & 8.04 & 8.03 & 9.58 & 9.58 & 8.21 & 7.86 & 6.11 & 6.11 & 6.88 & 6.88 & 9.41 & 9.71 \\
\hline Chile & $30^{\circ}$ & $32^{\circ}$ & 7.89 & 7.80 & 9.58 & 9.58 & 8.93 & 8.93 & 5.00 & 3.89 & 6.25 & 6.88 & 9.71 & 9.71 \\
\hline Brasil & $42^{\circ}$ & $44^{\circ}$ & 7.38 & 7.38 & 9.58 & 9.58 & 7.86 & 7.50 & 4.44 & 4.44 & 5.63 & 6.25 & 9.41 & 9.12 \\
\hline Panamá & $44^{\circ}$ & $47^{\circ}$ & 7.35 & 7.08 & 9.58 & 9.58 & 7.14 & 6.43 & 5.56 & 5.56 & 5.63 & 5.00 & 8.82 & 8.82 \\
\hline Argentina & $54^{\circ}$ & $52^{\circ}$ & 6.63 & 6.84 & 8.75 & 8.75 & 5.00 & 5.71 & 5.56 & 5.56 & 5.63 & 6.25 & 8.24 & 7.94 \\
\hline México & $53^{\circ}$ & $57^{\circ}$ & 6.67 & 6.68 & 8.75 & 8.33 & 6.07 & 6.07 & 5.00 & 6.67 & 5.00 & 5.00 & 8.53 & 7.35 \\
\hline $\begin{array}{c}\text { República } \\
\text { Dominicana }\end{array}$ & $74^{\circ}$ & $59^{\circ}$ & 6.13 & 6.67 & 9.17 & 8.75 & 4.29 & 5.71 & 3.33 & 5.00 & 5.63 & 6.25 & 8.24 & 7.65 \\
\hline Colômbia & $67^{\circ}$ & $62^{\circ}$ & 6.40 & 6.55 & 9.17 & 9.17 & 4.36 & 7.14 & 5.00 & 3.89 & 4.38 & 3.75 & 9.12 & 8.82 \\
\hline Peru & $75^{\circ}$ & $63^{\circ}$ & 6.11 & 6.54 & 8.75 & 9.17 & 3.29 & 5.00 & 5.56 & 5.00 & 5.00 & 5.00 & 7.94 & 8.53 \\
\hline El Salvador & $70^{\circ}$ & $64^{\circ}$ & 6.22 & 6.53 & 9.17 & 9.17 & 5.43 & 6.07 & 3.89 & 3.89 & 4.38 & 5.00 & 8.24 & 8.53 \\
\hline Paraguai & $71^{\circ}$ & $71^{\circ}$ & 6.16 & 6.26 & 7.92 & 8.33 & 5.00 & 5.36 & 5.00 & 5.00 & 4.38 & 4.38 & 8.53 & 8.24 \\
\hline Equador & $92^{\circ}$ & $79^{\circ}$ & 5.64 & 5.87 & 7.83 & 8.25 & 4.29 & 4.64 & 5.00 & 5.00 & 3.13 & 4.38 & 7.94 & 7.06 \\
\hline Honduras & $69^{\circ}$ & $80^{\circ}$ & 6.25 & 5.84 & 8.33 & 8.75 & 6.43 & 5.71 & 4.44 & 3.89 & 5.00 & 4.38 & 7.06 & 6.47 \\
\hline Guatemala & $77^{\circ}$ & $82^{\circ}$ & 6.07 & 5.81 & 8.75 & 7.92 & 6.79 & 6.07 & 2.78 & 3.33 & 4.38 & 4.38 & 7.65 & 7.35 \\
\hline Bolívia & $81^{\circ}$ & $83^{\circ}$ & 5.98 & 5.79 & 8.33 & 7.00 & 5.71 & 5.00 & 4.44 & 5.56 & 3.75 & 3.75 & 7.65 & 7.65 \\
\hline Nicarágua & $89^{\circ}$ & $94^{\circ}$ & 5.68 & 5.32 & 8.25 & 6.17 & 5.71 & 3.29 & 3.33 & 4.44 & 3.75 & 5.63 & 7.35 & 7.06 \\
\hline Venezuela & $93^{\circ}$ & $100^{\circ}$ & 5.42 & 5.07 & 7.00 & 5.25 & 3.64 & 4.29 & 5.56 & 5.56 & 5.00 & 4.38 & 5.88 & 5.88 \\
\hline
\end{tabular}

Fonte: The Economist, 2006-2014

A democracia, como regra prática, tornou-se uma imposição formal na América Latina, ainda que o personalismo tenha predominado na maior parte dos sistemas político-partidários nacionais.

\section{Alguns indicadores da democracia na América Latina em perspectiva}

Entre as várias instituições que fazem pesquisas e surveys periódicos sobre qualidade da democracia The Economist é uma das fontes mais importantes, não só pela abrangência de sua pesquisa envolvendo 167 países como também pela quantidade de aspectos retratados, entre eles, processo eleitoral, funcionamento do governo, participação política, cultura política e liberdades civis.
A partir de notas atribuídas às diferentes variáveis, chega-se a uma pontuação que leva à colocação dos 167 países dentro de um ranking geral. No quadro a seguir, traçamos um comparativo dos índices dos 18 países latino-americanos nos anos de 2006 - quando foi criado o índice - e 2014. O quadro está ordenado em ordem decrescente pelo ano de 2014, levando em conta a posição de cada país dentro do ranking geral de democracia.

No geral, podemos aferir que quatro países se mantiveram na liderança: Uruguai - país que mais incrementou seus índices entre os quatro primeiros - Costa Rica, Chile e Brasil. Dos 18 países, o que mais melhorou seus indicadores foi a República Dominicana (de $74^{\circ}$ para $59^{\circ}$ ), e o que mais piorou foi Honduras (de $69^{\circ}$ para $80^{\circ}$ ). Não se pode estabelecer, contudo, uma regionalização mais pormenorizada dessas variações. No Cone Sul, o Paraguai destoa com uma avaliação menor. Entre os países andinos, em geral, mal pontuados, o 
Quadro 1.2 - Classificação dos 18 países da América Latina por tipo de democracia

\begin{tabular}{|c|c|c|}
\hline & 2006 & 2014 \\
\hline Democracias plenas & $\begin{array}{c}\text { Costa Rica } \\
\text { Uruguai }\end{array}$ & $\begin{array}{c}\text { Costa Rica } \\
\text { Uruguai }\end{array}$ \\
\hline Democracias deficitárias & $\begin{array}{c}\text { Argentina } \\
\text { Bolívia } \\
\text { Brasil } \\
\text { Chile } \\
\text { Colômbia } \\
\text { El SalvadorGuatemala } \\
\text { Honduras } \\
\text { México } \\
\text { Panamá } \\
\text { Paraguai } \\
\text { Peru } \\
\text { República Dominicana }\end{array}$ & $\begin{array}{c}\text { Argentina } \\
\text { Brasil } \\
\text { Chile } \\
\text { Colômbia } \\
\text { El Salvador } \\
\text { México } \\
\text { Panamá } \\
\text { Paraguai } \\
\text { Peru } \\
\text { República Dominicana }\end{array}$ \\
\hline Regimes híbridos & $\begin{array}{l}\text { Equador } \\
\text { Nicarágua } \\
\text { Venezuela }\end{array}$ & $\begin{array}{c}\text { Bolívia } \\
\text { Equador } \\
\text { Guatemala } \\
\text { Honduras } \\
\text { Nicarágua } \\
\text { Venezuela }\end{array}$ \\
\hline
\end{tabular}

Fonte: The Economist, 2006-2014

Chile apresenta-se como um caso de sucesso. Na América Central, quase sempre pior colocada, o Panamá destaca-se positivamente.

Por outro lado, em que pesem os baixos indicadores, a América Latina tem apenas quatro países que se situavam, em 2014, abaixo da $80^{a}$ posição no que toca ao índice de democracia política: Guatemala, Bolívia, Nicarágua e Venezuela.

Levando-se em conta estes e outros índices, The Economist faz um mapa da democracia no mundo classificando-a em quatro grandes tipos: plenas, deficitárias, híbridas e autoritárias ${ }^{5}$. Neste último grupo, em 2014, não havia nenhum país latino-americano. A maior parte desses regimes considerados autoritários por The Economist situava-se na África e na Ásia.

Na comparação com 2006, Bolívia, Guatemala e Honduras deixaram de ser democracias deficitárias em 2014 e tornaram-se regimes híbridos, ou seja, regimes que embora pratiquem formalmente a democracia representativa têm desempenho menos positivo nos aspectos de funcionamento do governo, participação e cultura política e liberdades civis. Por esses índices, ainda, entre os países examinados, apenas Uruguai e Costa Rica eram democracias plenas no continente em 2006 e assim continuaram em 2014. O Chile, que por pouco não foi considerado um regime democrático pleno em 2006 - tinha uma pontuação de 7.89 - afastou-se ainda mais dessa categoria, especialmente pela acentuada queda na participação política. O Brasil, por sua vez, permaneceu numa posição intermediária.

Outras instituições de pesquisa caminham na mesma direção de elencar as democracias latino-americanas. Este é o caso do IDD Lat - Índice de Desenvolvimento Democrático da América Latina, que se dedica a aferir o desenvolvimento democrático de cada país a partir de quatro dimensões: 1) democracia dos cidadãos; 2) democracia das instituições; 3) democracia social e humana; e 4) democracia econômica. Comparando os anos de 2002 e 2014, vê-se uma melhora nos índices em apenas sete dos 18 países (Uruguai, Argentina, Peru, Equador, Brasil, Paraguai e Venezuela). De acordo com essa metodologia, o Chile é incluído entre os países de alto IDD, além de Uruguai e Costa Rica. O Brasil fica aqui em uma posição baixa, mas não entre os que apresentam condições mínimas de desenvolvimento democrático.

Na comparação entre os índices de 2002 e 2014, deve-se salientar que houve algumas mudanças metodológicas nos dois anos referidos. Em 2014, por exemplo, já não mais se pontuava a legalidade do regime democrático, assim como trouxe a novidade de agregar índices como "mortalidade infantil" e "matrícula" nos quesitos "saúde" e "educação", respectivamente. Apesar disso, em todos os anos em que foi aferida, a pesquisa priorizou as dimensões das liberdades civis, dos direitos políticos, da qualidade institucional e da eficiência política. 
Quadro 1.3 - Índice de Desenvolvimento Democrático em 18 países da América Latina (IDD)

\begin{tabular}{|c|c|c|c|}
\hline País & 2002 & 2014 & Nível de IDD \\
\hline Uruguai & 9,736 & 10,000 & Alto \\
\hline Chile & 8,757 & 8,523 & Alto \\
\hline Costa Rica & 8,575 & 8,485 & Alto \\
\hline Argentina & 5,247 & 6,650 & Médio \\
\hline Peru & 4,352 & 6,415 & Médio \\
\hline México & 6,340 & 5,019 & Médio \\
\hline El Salvador & 5,544 & 4,810 & Médio \\
\hline Panamá & 8,309 & 4,768 & Médio \\
\hline Equador & 1,694 & 4,640 & Baixo \\
\hline Brasil & 3,932 & 4,197 & Baixo \\
\hline Bolívia & 4,150 & 3,292 & Baixo \\
\hline Colômbia & 5,254 & 3,230 & Baixo \\
\hline Paraguai & 2,255 & 3,179 & Baixo \\
\hline Nicarágua & 2,963 & 2,630 & Baixo \\
\hline Venezuela & 2,243 & 2,406 & Baixo \\
\hline Honduras & 3,107 & 1,943 & Mínimo \\
\hline Republica Dominicana & -- & 1,770 & Mínimo \\
\hline Guatemala & 3,992 & 0,876 & Mínimo \\
\hline
\end{tabular}

Fonte: IDD Lat, 2002-2014

Quadro 1.4 - Países sem democracia eleitoral na América Latina

\begin{tabular}{|c|c|}
\hline $\begin{array}{c}\text { Países em que não há } \\
\text { democracia eleitoral (2014) }\end{array}$ & $\begin{array}{c}\text { Último ano em que houve } \\
\text { democracia eleitoral }\end{array}$ \\
\hline Nicarágua & 2010 \\
\hline Venezuela & 2007 \\
\hline
\end{tabular}

Fonte: Freedom House, 2015

Essas diferenças de classificação, oriundas de metodologias distintas, não desqualificam conclusões mais amplas no sentido de alertar que alguns países vêm mostrando, nos últimos anos, tendências preocupantes. $\mathrm{Ou}$ seja, os indicadores, em geral, não mostram um processo linear de melhora. Quando tomamos os dados da Freedom House, por exemplo, instituição que lista países que têm ou não democracia eleitoral, vemos que, em 2014, dois países da América Latina afastaram-se desse quesito, fundamental para medir a qualidade da democracia.

Em comparação com as pesquisas feitas por The Economist (quadro 1.1), vemos que, a partir de uma das variáveis desta instituição ("processo eleitoral e pluralismo”), os resultados são análogos. Segundo The Economist, Venezuela e Nicarágua ocupavam em 2014 as piores colocações nesse aspecto entre os 18 países lati- no-americanos, reduzindo bastante sua pontuação em relação a 2006, o que confirma a pesquisa da Freedom House, que indica que estes são os únicos países da região que em 2014 não possuíam democracia eleitoral. Esses são também dois países em que lideranças pessoais têm se sobreposto aos processos políticos regulares.

Quando se trata de saber o apoio que as sociedades dedicam à democracia, os resultados são desafiadores. Venezuela, cujos indicadores democráticos estão entre os mais baixos, é o segundo país em que a população mais apoia a democracia, como se pode ver no quadro que segue.

O Chile, por sua vez, quase sempre liderando a maioria dos indicadores da qualidade democrática, apresenta um apoio fraco à democracia (55\%), longe, por exemplo, dos $78 \%$ do Uruguai. Além disso, esse é 
Quadro 1.5 - Apoio à democracia em 18 países da América Latina

\begin{tabular}{|c|c|c|c|}
\hline País & Democracia (\%) & Autoritarismo (\%) & Indiferentes (\%) \\
\hline Uruguai & 78 & 15 & 10 \\
\hline Venezuela & 71 & 19 & 11 \\
\hline Costa Rica & 69 & 9 & 10 \\
\hline Argentina & 68 & 17 & 12 \\
\hline República Dominicana & 65 & 9 & 8 \\
\hline Bolívia & 56 & 15 & 15 \\
\hline Panamá & 55 & 14 & 16 \\
\hline Chile & 55 & 15 & 26 \\
\hline Peru & 54 & 17 & 18 \\
\hline Nicarágua & 53 & 12 & 19 \\
\hline El Salvador & 50 & 13 & 20 \\
\hline México & 49 & 19 & 25 \\
\hline Equador & 49 & 19 & 19 \\
\hline Colômbia & 48 & 13 & 23 \\
\hline Honduras & 47 & 13 & 21 \\
\hline Paraguai & 45 & 34 & 17 \\
\hline Brasil & 44 & 19 & 24 \\
\hline Guatemala & 38 & 21 & 22 \\
\hline
\end{tabular}

Fonte: Latinobarómetro, 1995-2013

o país com o maior percentual de indiferença quando se trata de escolher entre democracia e autoritarismo (26\%). O Brasil, em termos de apoio à democracia (44\%), está à frente apenas da Guatemala, com 38\%, e depois do Paraguai, país que mais apoia o autoritarismo.

Finalmente, precisamos nos deter sobre a participação feminina. As modernas e estáveis democracias destacam-se por terem altos níveis de participação feminina na política e na economia. Quando trazemos este indicador para a América Latina, os dados são paradoxais, como mostra a pesquisa do Inter-Parlamentary Union para 190 países $^{6}$. Se analisarmos as três mais importantes democracias da região, Costa Rica, Chile e Uruguai, nota-se no quadro abaixo que apenas a Costa Rica tem participação feminina expressiva - está na $26^{\mathrm{a}}$ posição entre os 190 países -, enquanto o Chile, mesmo com uma presidente mulher, cai para a $87^{\mathrm{a}}$, e o Uruguai fica na $100^{a}$. O Brasil encontra-se na $116^{a}$ posição, a pior da região, apesar de ter uma mulher presidente, reeleita para um segundo mandato.

Países considerados por The Economist como regimes híbridos em 2014 apresentavam, no entanto, níveis altos de participação de mulheres para os padrões mundiais, entre eles, Bolívia, Equador, Nicarágua e Honduras, donde se depreende que esta é uma variável que precisa ser examinada com mais acuidade no contexto de outras variáveis que definem o sistema político-eleitoral e a qualidade da democracia. Constitui-se certamente um importante tema de reflexão para não corrermos o risco de simplificações.

Quando tomamos indicadores que informam sobre as dimensões sociais da democracia, podemos observar que, para os 18 países selecionados, os dados, embora preocupantes, sinalizam lento progresso. Dados do Banco Mundial indicam que a América Latina tem apresentado algumas melhorias, mesmo que as desigualdades ainda sejam muito grandes dentro de cada país e entre os países. É isso também o que mostra o PNUD (Programa das Nações Unidas para o Desenvolvimento) entre os anos de 2003 e 2012. Por esses dados, todos os países, ainda que de forma descontinuada, têm diminuído a desigualdade, exceto Costa Rica, Guatemala e Colômbia. Entre os que mais melhoraram estão Peru, Equador, Brasil, República Dominicana e Panamá, os dois últimos não integrantes do movimento "onda rosa" (Silva, 2014). 
Quadro 1.6 - Representação das mulheres em 18 países da América Latina - 2015

\begin{tabular}{|c|c|c|c|}
\hline País & $\begin{array}{c}\text { Ranking (entre } 190 \\
\text { países) }\end{array}$ & $\begin{array}{c}\text { Câmara dos Deputados } \\
\text { (\% de mulheres) }\end{array}$ & $\begin{array}{l}\text { Senado (\% de } \\
\text { mulheres) }\end{array}$ \\
\hline Bolívia & $2^{\circ}$ & 53,1 & 47,2 \\
\hline Equador & $8^{\circ}$ & 41,6 & * \\
\hline Nicarágua & $14^{\circ}$ & 39,1 & * \\
\hline México & $16^{\circ}$ & 38,0 & 33,6 \\
\hline Argentina & $21^{\circ}$ & 36,2 & 38,9 \\
\hline Costa Rica & $26^{\circ}$ & 33,3 & * \\
\hline El Salvador & $27^{\circ}$ & 32,1 & * \\
\hline Honduras & $46^{\circ}$ & 25,8 & * \\
\hline Peru & $60^{\circ}$ & 22,3 & * \\
\hline Republica Dominicana & $65^{\circ}$ & 20,8 & 9,4 \\
\hline Colômbia & $71^{\circ}$ & 19,9 & 22,5 \\
\hline Panamá & $74^{\circ}$ & 19,3 & * \\
\hline Venezuela & $83^{\circ}$ & 17,0 & * \\
\hline Chile & $87^{\circ}$ & 15,8 & 15,8 \\
\hline Paraguai & $89^{\circ}$ & 15,0 & 20,0 \\
\hline Guatemala & $98^{\circ}$ & 13,3 & * \\
\hline Uruguai & $100^{\circ}$ & 13,1 & 6,5 \\
\hline Brasil & $116^{\circ}$ & 9,9 & 16,0 \\
\hline
\end{tabular}

* Sistema unicameral

Fonte: Inter-Parlamentary Union, 2015

Quadro 1.7 - Índice de Desenvolvimento Humano em 18 países da América Latina

\begin{tabular}{|c|c|c|c|c|c|}
\hline Países & $\begin{array}{c}\text { Ranking } \\
\mathbf{( 1 8 7} \text { países) }\end{array}$ & $\mathbf{2 0 1 0}$ & $\mathbf{2 0 1 1}$ & $\mathbf{2 0 1 2}$ & $\mathbf{2 0 1 3}$ \\
\hline Chile & $\mathbf{4 1 ^ { \circ }}$ & $\mathbf{0 . 8 0 8}$ & 0.815 & 0.819 & 0.822 \\
\hline Argentina & $\mathbf{4 9 ^ { \circ }}$ & 0.799 & 0.804 & 0.806 & 0.808 \\
\hline Uruguai & $50^{\circ}$ & 0.779 & 0.783 & 0.787 & 0.790 \\
\hline Panamá & $65^{\circ}$ & 0.759 & 0.757 & 0.761 & 0.765 \\
\hline Venezuela & $67^{\circ}$ & 0.759 & 0.761 & 0.763 & 0.764 \\
\hline Costa Rica & $68^{\circ}$ & 0.750 & 0.758 & 0.761 & 0.763 \\
\hline México & $71^{\circ}$ & 0.748 & 0.752 & 0.755 & 0.756 \\
\hline Brasil & $79^{\circ}$ & 0.739 & 0.740 & 0.742 & 0.744 \\
\hline Peru & $82^{\circ}$ & 0.722 & 0.727 & 0.734 & 0.737 \\
\hline Colômbia & $98^{\circ}$ & 0.706 & 0.710 & 0.708 & 0.711 \\
\hline Equador & $98^{\circ}$ & 0.701 & 0.705 & 0.708 & 0.711 \\
\hline República Dominicana & $102^{\circ}$ & 0.691 & 0.695 & 0.698 & 0.700 \\
\hline Paraguai & $111^{\circ}$ & 0.669 & 0.672 & 0.670 & 0.676 \\
\hline Bolívia & $113^{\circ}$ & 0.658 & 0.661 & 0.663 & 0.667 \\
\hline El Salvador & $115^{\circ}$ & 0.652 & 0.657 & 0.660 & 0.662 \\
\hline Guatemala & $125^{\circ}$ & 0.613 & 0.620 & 0.626 & 0.628 \\
\hline Honduras & $129^{\circ}$ & 0.612 & 0.615 & 0.616 & 0.617 \\
\hline Nicarágua & $132^{\circ}$ & 0.604 & 0.608 & 0.611 & 0.614 \\
\hline
\end{tabular}

Fonte: PNUD, 2014 
Quadro 1.8 - Níveis de IDH em 18 países da América Latina

\begin{tabular}{|c|c|}
\hline IDH muito alto & Chile \\
& Argentina \\
\hline & Uruguai \\
& Panamá \\
& Venezuela \\
& Costa Rica \\
& México \\
& Brasil \\
& Peru \\
& Colômbia \\
& Equador \\
& República Dominicana \\
& Paraguai \\
& Bolívia \\
& El Salvador \\
& Guatemala \\
& Honduras \\
& Nicarágua \\
\hline
\end{tabular}

Fonte: PNUD, 2014

O Índice de Desenvolvimento Humano (IDH), construído para um conjunto de 187 países, indica também um movimento positivo em todos os 18 países?

À exceção de Colômbia e Paraguai, que variaram negativamente apenas uma vez (ambos de 2011 para 2012) e Panamá (com queda de 2010 para 2011), os demais países, foco da nossa investigação, melhoraram continuadamente seus índices. Chile, Peru e Guatemala foram os países que mais melhoraram nesse item nos quatro anos pesquisados (o primeiro variou positivamente 0.14 , e os outros dois, 0.15). O quadro acima ratifica outros dados que levantamos (como nos quadros 1.1 e 1.3), mostrando o quanto um esforço progressivo no desenvolvimento democrático pode acarretar melhoras sociais e econômicas para a população. A seguir, preparamos outro quadro que agrega os 18 países nos níveis de IDH indicados pelo PNUD.

Como podemos ver, mais da metade dos países analisados (dez) têm um IDH considerado alto e nenhum está enquadrado como possuidor de IDH baixo. Estes são dados alentadores se considerarmos as possibilidades de corrigir a histórica desigualdade da região.

Por outro lado, as informações sobre corrupção continuam tendo contornos pesados se levarmos em conta as várias pesquisas a esse respeito. Usando os dados da Transparency International, elaboramos o quadro abaixo que informa sobre a percepção da corrupção nos 18 países entre 2012 e 2014. Paradoxalmente, a
Venezuela, país que mais apoia a democracia, é também o que mais se percebe como corrupto.

Como em outros quadros (1.1 e 1.3), aqui, mais uma vez, constatamos a liderança de Costa Rica, Uruguai e Chile (não necessariamente nessa ordem). Outro fator a destacar é a quantidade de países abaixo da $100^{\circ}$ posição (10, no total), nesse conjunto de 175 países. Fator marcante é que nenhum dos países melhorou progressivamente sua posição nos três anos pesquisados. A corrupção é uma realidade incomodamente estável na América Latina.

Finalmente, uma nota sobre violência. Segundo o Homicide Monitor do Igarapé Institute, a América Latina apresenta 33\% dos homicídios no mundo, embora reúna apenas $8 \%$ da população global ${ }^{8}$. Em termos absolutos, a região concentra cinco dos 20 mais violentos países do mundo: Brasil, México, Colômbia, Venezuela e Guatemala. Além do mais, 14 dos 20 países com maiores taxas de homicídios estão na América Latina e no Caribe (entre eles, Honduras, Jamaica, Guatemala, Colômbia, México, Brasil e Venezuela). Uma em cada cinco pessoas mortas violentamente no mundo é brasileira, colombiana ou venezuelana. Assim como a corrupção, a violência continua a ser uma emblemática e desconfortável marca de toda a América Latina.

Antes de encerrarmos esta seção do artigo vamos resumir, à luz das informações indicadas acima, como o Brasil se situa entre os 18 países. Isso ajudará a organizar 
Quadro 1.9 - Percepção da corrupção em 18 países da América Latina*

\begin{tabular}{|c|c|c|c|c|}
\hline Países & Ranking (175 países) & 2012 & 2013 & 2014 \\
\hline Uruguai & $21^{\circ}$ & 72 & 73 & 73 \\
\hline Chile & $21^{\circ}$ & 72 & 71 & 73 \\
\hline Costa Rica & $47^{\circ}$ & 54 & 53 & 54 \\
\hline Brasil & $69^{\circ}$ & 43 & 42 & 43 \\
\hline El Salvador & $80^{\circ}$ & 38 & 39 & 39 \\
\hline Peru & $85^{\circ}$ & 38 & 38 & 38 \\
\hline Colômbia & $94^{\circ}$ & 36 & 36 & 37 \\
\hline Panamá & $94^{\circ}$ & 38 & 35 & 37 \\
\hline Bolívia & $103^{\circ}$ & 34 & 34 & 35 \\
\hline México & $103^{\circ}$ & 34 & 34 & 35 \\
\hline Argentina & $107^{\circ}$ & 35 & 34 & 34 \\
\hline Equador & $110^{\circ}$ & 32 & 35 & 33 \\
\hline República Dominicana & $115^{\circ}$ & 32 & 39 & 32 \\
\hline Guatemala & $115^{\circ}$ & 33 & 29 & 32 \\
\hline Honduras & $126^{\circ}$ & 28 & 26 & 29 \\
\hline Nicarágua & $133^{\circ}$ & 29 & 28 & 28 \\
\hline Paraguai & $150^{\circ}$ & 25 & 24 & 24 \\
\hline Venezuela & $161^{\circ}$ & 19 & 20 & 19 \\
\hline
\end{tabular}

* Quanto mais perto de zero, mais corrupto.

Fonte: Transparency International, 2015

a segunda parte que fará uma análise em profundidade do caso brasileiro.

Nos indicadores sobre democracia o país fica atrás apenas de Uruguai, Costa Rica e Chile. Este índice (quadro 1.1) leva em conta o processo eleitoral e o pluralismo, o funcionamento do governo, a participação política, a cultura política e as liberdades civis. Neste aspecto mais global, de fato, o país tem mostrado competência institucional. Um fator positivo a ser considerado é a votação eletrônica que imprimiu agilidade e confiança às eleições em todos os níveis.

Quando se trata de classificar os países por tipo de democracia (quadro 1.2) vemos que o Brasil fica numa situação intermediária (democracia deficitária) - mesma posição ocupada quando o tema é o IDH (quadro 1.6). Em vários outros aspectos situa-se em posição mais baixa, especialmente quanto aos índices de desenvolvimento democrático (quadro 1.3), apoio à democracia (quadro 1.5), incorporação das mulheres ao processo representativo (quadro 1.6) e percepção de corrupção (quadro 1.9). Nestes dois últimos aspectos a posição do país é extremamente desfavorável apesar da sua estabilização democrática. Este é, contudo, um quadro dinâmico. Ao olhar o Brasil com mais atenção, percebemos que mudanças pontuais vêm ocorrendo no sentido de lastrear práticas democráticas mais eficazes, ainda que alguns resultados sejam modestos, especialmente quando se trata da participação feminina na política representativa.

\section{Brasil e a qualidade da democracia em perspectiva}

Alguns fatores relevantes a ser considerados quando se analisa a democracia brasileira são, sem dúvida, a alta fragmentação partidária, acelerada nos governos de esquerda a partir de 2002, e a precariedade dos controles internos e externos às instituições políticas, fenômeno que se repete na maioria dos países latino-americanos. Em toda a região, também ocorreram mudanças expressivas nos sistemas partidários, sinalizando que os partidos ainda são expressões efetivas das mudanças políticas que ocorrem nas sociedades.

Embora o Brasil apresente um dos mais baixos níveis de adesão à democracia na América Latina, informações do instituto Datafolha, indicam que esses valores vêm crescendo (Moisés, 2014). Comparando os anos de 1989 e 2014, o Datafolha aponta os seguintes resultados que mostram um crescente e estável movimento favorável aos valores democráticos. 
Quadro 2.0 - Perfil dos valores democráticos no Brasil em 1989 e 2014 (\%)

\begin{tabular}{|c|c|c|}
\cline { 2 - 3 } \multicolumn{1}{c|}{} & $\mathbf{1 9 8 9}$ & $\mathbf{2 0 1 4}$ \\
\hline $\begin{array}{c}\text { Democracia é preferível aos } \\
\text { demais regimes }\end{array}$ & 43 & 66 \\
\hline $\begin{array}{c}\text { Ditadura é preferível; } \\
\text { melhor }\end{array}$ & 18 & 12 \\
\hline Tanto faz & 22 & 15 \\
\hline Não sabe & 17 & 7 \\
\hline
\end{tabular}

Fonte: Datafolha, 1989-2014

Com a redemocratização, o calendário eleitoral no Brasil tem sido rigorosamente respeitado. A Justiça Eleitoral tem tido um papel civilizatório, criando regras para a propaganda das campanhas, e tem inovado com a urna eletrônica e o voto biométrico. Contudo, não tem sido ágil o bastante para acompanhar as diversas formas de captação ilícita de recursos e os abusos do poder econômico'.

Não obstante esses percalços, o Brasil é um dos países latino-americanos com mais solidez e estabilidade em suas instituições políticas, econômicas e jurídicas. Desde que os militares deixaram o poder, em 1985, depois de 21 anos de ditadura, têm predominado o Estado de direito, a divisão formal de poderes e o afastamento dos militares da política. Não houve qualquer prontidão nos quartéis nem manifestos militares. $\mathrm{O}$ país ganhou uma Constituição democrática em 1988 e poucos anos depois enfrentou uma das piores crises de sua história republicana: em 1993, houve o impeachment de Fernando Collor de Mello, presidente da República, depois de longo confronto político e jurídico e de grande mobilização popular. A corrupção foi o grande fator a impulsionar as denúncias que levaram ao seu afastamento, mas tudo foi equacionado pelas vias constitucionais. $\mathrm{Na}-$ quela ocasião tivemos uma crise de legitimidade de um presidente e seu subsequente afastamento, mas todos os procedimentos legais foram seguidos, sem qualquer apelo militar, ao contrário do que se observou em outros países da América Latina, conforme mostra Pion-Berlin (2008). Não se fortaleceu também qualquer movimento explícito e duradouro pela reforma da Constituição em moldes de uma demanda por um pacto fundador, ou refundador da República, como ocorreu em outros países da região, em particular nos andinos.

No Brasil, a personalização do poder tem sido baixa, mesmo considerando a popularidade do ex-presidente Luiz Inácio Lula da Silva (2003-2010), cujos índices de aprovação chegaram a mais de $80 \%$. A aprovação do presidente, contudo, não se converteu automaticamente em votos para os candidatos que ele apoiou nos estados nem para seu partido, o PT (Partido dos Trabalhadores). Segundo Santos (2015), o PT aumentou gradativamente sua representação na Câmara dos Deputados até 2002, quando elegeu $18 \%$ dos representantes na Casa. A partir de então, já com o partido no poder, a representação foi caindo, chegando a $13 \%$ em 2014. Retração ainda maior ocorreu na representação das câmaras estaduais e municipais. Dessa forma, o sucesso do líder, Lula da Silva, não correspondeu ao fortalecimento de seu partido. Ao contrário, não só seu partido diminuiu de tamanho como os presidentes eleitos pelo PT (Lula e Dilma Rousseff) foram obrigados a se apoiar numa plêiade de novos partidos criados em circunstâncias ah hoc.

Em se tratando das instituições de Estado, vemos que carecem de confiança expressiva por parte da população. $\mathrm{O}$ mesmo ocorre em relação aos três poderes da República: nenhum goza de grande prestígio popular, especialmente o Legislativo e os partidos políticos, que recebem avaliações muito baixas conforme se pode ver abaixo.

Juntamente com essa desconfiança, é preciso pontuar que a representação política, embora sendo parte da cultura política da elite brasileira (Lamounier, 1981), não significou tranquila democratização do poder. Quando se examina o sistema partidário, nota-se que, ao contrário da maior parte dos países sul-americanos, o Brasil tem sido historicamente um exemplo de descontinuidade e de fragilidade partidária. Ao longo da República, o país conheceu seis sistemas partidários. $\mathrm{O}$ primeiro estende-se de 1889 até a Revolução de 1930, que trouxe Getúlio Vargas ao poder. Tratava-se de um sistema partidário regional, oligárquico, fechado e sem o voto secreto. Com a chegada de Vargas ao poder, esse 
Quadro 2.1 - Confiança nas instituições no Brasil (\%)

\begin{tabular}{|c|c|c|c|c|}
\hline Instituições & $\mathbf{2 0 1 0}$ & $\mathbf{2 0 1 1}$ & $\mathbf{2 0 1 2}$ & $\mathbf{2 0 1 3}$ \\
\hline Bombeiros & 85 & 86 & 83 & 77 \\
\hline Igreja & 73 & 72 & 71 & 66 \\
\hline Forças Armadas & 69 & 72 & 71 & 64 \\
\hline Meios de comunicação & 67 & 65 & 62 & 56 \\
\hline Empresas & 60 & 59 & 57 & 51 \\
\hline Organizações civis & 61 & 59 & 57 & 49 \\
\hline Polícia & 52 & 55 & 54 & 48 \\
\hline Bancos & 58 & 57 & 56 & 48 \\
\hline Escolas públicas & 60 & 55 & 55 & 47 \\
\hline Poder judiciário & 53 & 49 & 53 & 46 \\
\hline Presidente da República & 69 & 60 & 63 & 42 \\
\hline Governo Federal & 59 & 53 & 53 & 41 \\
\hline Eleições & 56 & 52 & 47 & 41 \\
\hline Governo do seu município & 50 & 47 & 45 & 41 \\
\hline Sindicatos & 44 & 44 & 44 & 37 \\
\hline Sistema público de saúde & 47 & 41 & 42 & 32 \\
\hline Congresso Nacional & 38 & 35 & 36 & 29 \\
\hline Partidos políticos & 33 & 28 & 29 & 25 \\
\hline
\end{tabular}

Fonte: Ibope, 2010-2013

sistema foi abolido, e recriaram-se outros partidos políticos (1933), ainda regionais e que seriam abolidos em seguida, quando da proclamação da ditadura do Estado Novo (1937-1945). Com a redemocratização do pós-guerra, o Brasil conheceu partidos nacionais proscritos pela ditadura militar em 1965. Essa ditadura instaurou o bipartidarismo tutelado, que ela mesma reformou em 1979, levando a cabo a quinta reforma partidária da República $^{10}$. Com a redemocratização, em 1985, um novo sistema foi criado, e depois corroborado pela Carta Democrática de 1988, garantindo ampla pluralidade política e liberdade partidária.

O objetivo deste breve histórico é destacar três pontos. Primeiro, a elite política do país, embora aceite a regra formal da eleição para formar governos, não tem, ao longo da história, respeitado os partidos como instrumentos de representação da sociedade (Souza, 1976). Sempre que os partidos passaram a representar setores mais amplos da sociedade ou interesses classistas dos trabalhadores, a elite, civil ou militar, optou por sua destruição de forma arbitrária. Dessa forma, no Brasil, é frequente associarmos parte da sua fragilidade democrática a estas descontinuidade e deslegitimidade do sistema partidário, ao contrário do que ocorreu em países como Argentina, Chile e Uruguai, entre outros, marcados por fortes estruturas partidárias que se renovaram lentamente.

Em segundo lugar, nas últimas três décadas, as elites políticas e governamentais têm sido bastante ágeis no período democrático em criar novos partidos de forma a favorecer maiorias governamentais, acomodar interesses e melhor disputar cargos.

Em terceiro lugar, queremos chamar a atenção para o fato de que grande parte dos países da América Latina que passaram por processos de ampliação da participação popular e formação de governos populares considerou a existência de partidos fortes e duradouros como um obstáculo à democracia. Países como Venezuela, Bolívia, Equador, Uruguai e Peru viram emergir, pelas urnas, outras forças políticas que se sobrepuseram às tradicionais estruturas partidárias. $\mathrm{O}$ Brasil, por sua vez, não tinha um forte sistema tradicional a destruir e fragmentou seu sistema de tal forma que qualquer partido no poder tem que firmar amplas e híbridas alianças visando à formação de maiorias e à governabilidade.

Finalmente, é necessária uma nota adicional sobre violência. Dados fornecidos pelo Social Progress Index de 2015 e elaborados pela agência Social Progress Imperative

10 Durante a ditadura militar, o Congresso Nacional foi fechado de outubro a novembro de 1966, de 13 de dezembro de 1968 a 15 de outubro de 1969 e de $1^{\circ}$ de abril de 1977 a 15 de abril de 1977. 
são reveladores ${ }^{11}$. Levando-se em conta indicadores como suprimento de necessidades básicas, saneamento, acesso à educação, oportunidades, renda e condições de meio ambiente, o Brasil ocupa uma confortável $44^{a}$ posição entre 133 países, apenas atrás de Uruguai e Chile na América do Sul. Quando se trata da segurança pessoal, dimensão que leva em conta crimes violentos, taxas de homicídios, mortes no trânsito, terror político (praticamente inexistente no país) e sensação de insegurança, o Brasil cai para a $122^{\mathrm{a}}$ posição entre 133 países analisados. Entre seus vizinhos, só a Venezuela está em pior situação.

\subsection{Partidos, programas e diretrizes políticas no Brasil}

Em 2015, o Brasil contava com 35 partidos legalizados e 28 representados no Congresso. Apesar disso, pode-se constatar que apenas dois têm pautado as disputas eleitorais para a Presidência: o PT e o PSDB (Partido da Social Democracia Brasileira). Um terceiro e importante partido a ser considerado é o PMDB (Partido do Movimento Democrático Brasileiro), fiel da balança para viabilizar governos. A importância desses partidos não se dá por seu apelo popular, já que nenhum deles é um partido de massas (Duverger, 1987).

Só $17 \%$ da população brasileira diziam ter, em dezembro de 2014, preferência partidária, e apenas 15 milhões (7,5\% da população) eram filiados a partidos ${ }^{12}$. A confiança nos partidos no Brasil é baixa, $25 \%$ conforme o quadro 2.1 , mas não destoa do que acontece pelo mundo: $33,4 \%$ na Suécia, 29,1\% na Finlândia, 18,3\% no Japão, 14,3\% na Austrália, 17,8\% no Reino Unido, 16,4\% na França e 13\% na Alemanha (Moisés, 2014). Desta forma, os valores na democracia não podem se reduzir ao prestígio de partidos nem mesmo ao do Congresso. Ou seja, como fizemos aqui, há que se pensar a democracia com valores e ferramentas diferentes daqueles que usávamos no fim do século XIX.A população, os mais jovens em particular, centra-se em valores atinentes à realização das capacidades individuais e se sente mais traída quando percebe que um governante não lhe permite usufruir desses direitos (Skocpol e Fiorina, 1999).

Contudo, mesmo pensando rumo a uma democracia de público, e não mais de partidos ${ }^{13}$, estes ainda são a maneira mais legítima de organizar as eleições e podem ser fontes de tendências doutrinárias e ideológicas sobre as relações do Estado com o mercado e sobre as questões sociais. Examinaremos partes dos programas dos três principais partidos brasileiros já citados, considerando, basicamente, suas concepções sobre liberalismo, democracia, socialismo, mercado, capitalismo, intervenção do Estado na economia, relações com a sociedade civil e minorias. Em que pese o fato de que programas partidários podem ser peças de ficção, nestes três casos, podem servir como fontes de informação sobre as orientações políticas do sistema político brasileiro.

O PT, partido mais à esquerda no espectro ideológico, apresenta um programa que, de fato, aponta para propostas anticapitalistas, defesa do "socialismo democrático" com participação popular e uma maior intervenção do Estado na economia. Ainda que no seu programa de governo reconheça alguma importância dos incentivos privados e estrangeiros para o desenvolvimento, vê os investimentos públicos como a melhor forma de fortalecer a economia brasileira. Em relação à sociedade civil, o PT defende a participação ativa da massa dos trabalhadores nas decisões políticas tomadas pelo Estado. Assim como o PSDB, menciona claramente a necessidade de estabelecer vínculos mais fortes com movimentos sociais, minorias étnicas e de gênero.

O PSDB tem, declaradamente, uma agenda social-democrata. Defende a inserção do país na economia global por meio de um maior e melhor desenvolvimento da indústria brasileira. Segundo seu programa, o problema brasileiro não é o subdesenvolvimento, e sim, a desigualdade de renda. Nas relações com a sociedade civil, faz uma nítida crítica à sua falta de capacidade de mobilizar a sociedade.

O PMDB é o partido com mais capilaridade geográfica ao longo do país e tem apresentado, na prática, uma grande plasticidade política. Pode ser considerado um partido de centro e, desde a redemocratização de 1985, tem sido o fiel da balança da política nacional ${ }^{14}$.

PSDB e PT revezaram-se na Presidência da República a partir de 1994 e têm polarizado as eleições presidenciais desde então. No entanto, considerando as eleições para os governadores dos 27 estados do país e para as assembleias estaduais e nacionais, verificamos um quadro bem diferente. Nestes casos, a competição com os demais partidos é intensa, e o rol de agremiações que consegue eleger candidatos é amplo ${ }^{15}$. Esta dissonância entre uma dinâmica política polarizada em dois partidos

11 Ver <http://www.socialprogressimperative.org> (último acesso: 07/06/2015).

12 Apenas o PMDB tem mais de 2 milhões de filiados (2.355.464), seguido pelo PT (1.588.058), PP (1.413.565) e PSDB (1.373.920), segundo o TSE (Tribunal Superior Eleitoral).

13 Sobre o papel dos partidos ao longo das experiências de governos representativos, ver Manin (1995).

14 Todas as informações são da página do TSE, disponível em <http://www.tse.jus.br/partidos/partidos-politicos/registrados-no-tse> (último acesso: 07/06/2015).

15 Um minucioso estudo sobre o assunto encontra-se em Melo (2015). 
no plano nacional visando às eleições presidenciais e outra, mais fragmentada, para lidar com as eleições majoritárias e proporcionais nos níveis estadual e municipal, produz normalmente um choque de orientações e contradições partidárias. A inteligibilidade do sistema partidário e eleitoral torna-se extremamente opaca para o eleitor, que, em meio a essa complicada e imbricada rede de alianças e acordos, enxerga com mais clareza as pessoas (os candidatos) do que os partidos.

\subsection{Partidos e fragmentação do Congresso Nacional no Brasil}

Na Câmara dos Deputados, a fragmentação partidária tem sido mais expressiva do que no Senado. No quadro abaixo, apresentamos a dispersão partidária nessas duas Casas entre 1994 e 2014.

Como se pode ver, tanto em 1994 quanto em 1998, 18 agremiações elegeram parlamentares para a Câmara dos Deputados. Em 2002, foram 19. Depois da chegada do PT ao poder, esse número cresceu substantivamente: na eleição de 2006, foram 21 partidos, em 2010, 23, e em 2014, o número chegou a 28. Em menor escala, a fragmentação também pode ser observada no Senado, com a maior dispersão ocorrida em 2010, quando foram eleitos dois terços do Senado distribuídos em 16 partidos.

É importante frisar que a proliferação de partidos não é uma inovação brasileira. Os demais países da América Latina seguem uma lógica parecida, principalmente a partir dos processos de transição política. Até o início dos anos 2000, apenas Costa Rica, Honduras e Paraguai tendiam ao bipartidarismo; os demais assistiram uma enorme fragmentação, ainda que longe da dimensão alcançada no Brasil (Alcántara Saez e Freidenberg, 2002).

Essa contundente fragmentação partidária brasileira produz incertezas quanto à governabilidade e obriga a realização de acordos que muitas vezes parecem estranhos ao entendimento do eleitorado, que não enxerga essas agremiações partidárias como fontes de recepção das suas demandas.

Por essas e outras razões, o país tem mantido uma ampla agenda de reformas políticas, e algumas importantes mudanças já foram implementadas. Em 1997, os partidos políticos passaram a ser obrigados a ter uma cota de, no mínimo, 30\% de candidatas mulheres, objetivando diminuir a falta de representatividade desse grupo. Outra importante iniciativa ocorreu em 2001, quando terminou a imunidade parlamentar para políticos que cometessem crimes comuns.

A lei de fidelidade partidária aprovada em 2007 foi outro passo crucial para aprimorar a vida partidária no Congresso Nacional. Por essa lei, dificultou-se a mu- dança de partido por parte dos representantes eleitos. Não raro, o político se elegia por um partido, tomava posse por outro e podia ainda trocar de agremiação durante o exercício do mandato (Melo, 2000). Normalmente, essas trocas eram feitas de forma a engrossar as fileiras de partidos governistas.

Além disso, por pressão de mecanismos de participação popular, garantidos pela Constituição de 1988, foi aprovada a chamada Lei da Ficha Limpa em 2010. Apoiada por mais de um milhão e meio de assinaturas, transformou-se em um importante instrumento de controle da qualidade dos candidatos. Pró́be a inscrição de candidatos que tenham sido condenados em instância judiciária por crimes de homicídio, contra o patrimônio público, corrupção, compra de votos, entre outros. Porém, a morosidade da Justiça brasileira impede que a lei seja aplicada com mais rigor.

Em 2012, outra importante mudança foi introduzida com a Lei de Acesso à Informação, que possibilitou a qualquer cidadão requerer aos órgãos públicos as informações que julgasse importantes. Além disso, obriga os órgãos de Estado e de governo a darem mais transparência a suas ações administrativas e financeiras.

O escândalo de corrupção de 2005, conhecido como Mensalão, deu margem à prisão de políticos e empresários. Nova investigação passou a ser feita pela Polícia Federal e pelo Ministério Público a partir de 2014, para apurar o desvio de dinheiro de empresas públicas e privadas para partidos políticos e campanhas eleitorais (Operação Lava-Jato). Estes escândalos fortaleceram os argumentos a favor das reformas partidárias e eleitorais, um processo que continua em curso.

Nesse quadro de demandas por reformas, a participação política é baixa em termos de mobilização popular, mas a participação eleitoral é alta, em função do voto obrigatório. Há tolerância política, respeito formal às liberdades civis, e o calendário eleitoral é respeitado. Apesar disso, a baixa empatia da população para com a política e os políticos tem sido constante, o que pode ser explicado a partir de três pontos fundamentais: a) falta de responsabilidade das lideranças e dos dirigentes dos partidos ao escolher os candidatos; b) inexistência de custos de transgressão para os partidos quando seus quadros são denunciados na Justiça e sobre os quais haja evidências de práticas ilícitas; e c) artimanhas usadas por partidos para mascarar contas de campanha.

Lembremos, ademais, que a pífia representação política de mulheres e de outras minorias no Brasil não chega a mobilizar a opinião pública ou a de líderes políticos. Paradoxalmente, desde 2002, quando se iniciam os governos do PT, mantém-se uma perversa estabilidade de indicadores extremamente baixos no que se refere à sua representação (Alves, 2012; Araújo, 2005). A desigualdade de gênero no mercado de trabalho também é uma das mais altas do mundo ${ }^{16}$. 
Quadro 2.2 - Fragmentação partidária no Congresso brasileiro

\begin{tabular}{|c|c|c|c|c|c|c|c|c|c|c|c|c|}
\hline \multirow[b]{2}{*}{ Partidos } & \multicolumn{2}{|c|}{1994} & \multicolumn{2}{|c|}{1998} & \multicolumn{2}{|c|}{2002} & \multicolumn{2}{|c|}{2006} & \multicolumn{2}{|c|}{2010} & \multicolumn{2}{|c|}{2014} \\
\hline & Câmara & Senado & Câmara & Senado & Câmara & Senado & Câmara & Senado & Câmara & Senado & Câmara & Senado \\
\hline PT & 49 & 4 & 59 & 3 & 91 & 10 & 83 & 2 & 88 & 11 & 70 & 2 \\
\hline PMDB & 107 & 14 & 99 & 12 & 75 & 9 & 89 & 4 & 79 & 16 & 66 & 5 \\
\hline PSDB & 62 & 9 & 83 & 4 & 70 & 8 & 66 & 5 & 43 & 5 & 54 & 4 \\
\hline PSD & -- & -- & -- & -- & -- & -- & -- & -- & -- & -- & 37 & 2 \\
\hline PPR/PPB/PP & 36 & 4 & 60 & 2 & 49 & -- & 41 & 1 & 41 & 4 & 36 & 1 \\
\hline PR & -- & -- & -- & -- & -- & -- & -- & -- & 41 & 3 & 34 & 1 \\
\hline PSB & 15 & 1 & 18 & 1 & 22 & 3 & 27 & 1 & 34 & 3 & 34 & 3 \\
\hline PTB & 31 & 3 & 31 & -- & 26 & 2 & 22 & 3 & 21 & 1 & 25 & 2 \\
\hline PFL/DEM & 89 & 11 & 105 & 5 & 84 & 14 & 65 & 6 & 43 & 2 & 22 & 3 \\
\hline PRB & -- & -- & -- & -- & -- & -- & 1 & -- & 8 & 1 & 21 & -- \\
\hline PDT & 34 & 4 & 25 & -- & 21 & 4 & 24 & 1 & 28 & 2 & 19 & 4 \\
\hline SD & -- & -- & -- & -- & -- & -- & -- & -- & -- & -- & 15 & -- \\
\hline PSC & 3 & -- & 2 & -- & 1 & -- & 9 & -- & 17 & 1 & 12 & -- \\
\hline PROS & -- & -- & -- & -- & -- & -- & -- & -- & -- & -- & 11 & -- \\
\hline PPS & 2 & 1 & 3 & -- & 15 & 1 & 22 & 1 & 12 & 1 & 10 & -- \\
\hline$P C$ do $B$ & 10 & -- & 7 & -- & 12 & -- & 13 & 1 & 15 & 1 & 10 & -- \\
\hline PV & 1 & -- & 1 & -- & 5 & -- & 13 & -- & 15 & -- & 8 & -- \\
\hline PSOL & -- & -- & -- & -- & -- & -- & 3 & -- & 3 & 2 & 5 & -- \\
\hline PHS & -- & -- & -- & -- & -- & -- & 2 & -- & 2 & -- & 5 & -- \\
\hline PTN & -- & -- & -- & -- & -- & -- & -- & -- & -- & -- & 4 & -- \\
\hline PMN & 4 & -- & 2 & -- & 1 & -- & 3 & -- & 4 & 1 & 3 & -- \\
\hline PRP & 1 & -- & -- & -- & -- & -- & -- & -- & 2 & -- & 3 & -- \\
\hline PEN & -- & -- & -- & -- & -- & -- & -- & -- & 2 & -- & 2 & -- \\
\hline PTC & -- & -- & -- & -- & -- & -- & 3 & -- & 1 & -- & 2 & -- \\
\hline PSDC & -- & -- & -- & -- & 1 & -- & -- & -- & -- & -- & 2 & -- \\
\hline PRTB & -- & -- & -- & -- & -- & -- & -- & 1 & 2 & -- & 1 & -- \\
\hline PSL & -- & -- & 1 & -- & 1 & -- & 1 & -- & 1 & -- & 1 & -- \\
\hline PT do B & -- & -- & -- & -- & -- & -- & -- & -- & 3 & -- & 1 & -- \\
\hline PL & 13 & 1 & 12 & -- & 26 & 2 & 23 & 1 & -- & -- & -- & -- \\
\hline PRONA & -- & -- & 1 & -- & 6 & -- & 2 & -- & -- & -- & -- & -- \\
\hline PAN & -- & -- & -- & -- & -- & -- & 1 & -- & -- & -- & -- & -- \\
\hline PDS/PPR & 52 & 2 & -- & -- & -- & -- & -- & -- & -- & -- & -- & -- \\
\hline PSD* & 3 & -- & 3 & -- & 4 & 1 & -- & -- & -- & -- & -- & -- \\
\hline PST & -- & -- & 1 & -- & 3 & -- & -- & -- & -- & -- & -- & -- \\
\hline PRN & 1 & -- & -- & -- & -- & -- & -- & -- & -- & -- & -- & -- \\
\hline Total & 513 & $54 * *$ & 513 & $27^{* * *}$ & 513 & $54 * *$ & 513 & $27 * * *$ & 513 & $54^{* *}$ & 513 & $27^{* * *}$ \\
\hline
\end{tabular}

* Fundido ao PTB em 2003.

** Eleição para preencher 2/3 da Casa.

*** Eleição para preencher 1/3 da Casa.

Fonte: TSE 
Quadro 2.3 - Índice de pobreza em 18 países da América Latina (\%)*

\begin{tabular}{|c|c|c|c|c|c|c|c|c|c|c|}
\hline Países & 2003 & 2004 & 2005 & 2006 & 2007 & 2008 & 2009 & 2010 & 2011 & 2012 \\
\hline Uruguai & 1,1 & 1,3 & 1,2 & 0,8 & 0,6 & 0,4 & 0,3 & 0,3 & 0,3 & 0,3 \\
\hline México & -- & 1,8 & 4,2 & 1,0 & -- & 1,3 & -- & 1,0 & -- & 1,0 \\
\hline Costa Rica & 4,5 & 4,2 & 3,1 & 3,2 & 1,8 & 2,2 & 2,6 & 1,2 & 1,2 & 1,2 \\
\hline República Dominicana & 5,2 & 6,8 & 4,6 & 3,7 & 3,4 & 3,2 & 2,7 & 2,4 & 2,4 & 2,4 \\
\hline El Salvador & 11,2 & 6,5 & 5,9 & 3,7 & 2,6 & 4,1 & 3,7 & 4,4 & 2,7 & 2,4 \\
\hline Peru & 7,3 & 5,6 & 6,4 & 5,4 & 5,2 & 4,0 & 3,1 & 2,4 & 2,6 & 2,5 \\
\hline Paraguai & 6,4 & 4,9 & 5,1 & 6,9 & 5,8 & 3,7 & 4,5 & 4,3 & 4,0 & 2,6 \\
\hline Panamá & 8,4 & 7,7 & 7,3 & 8,0 & 5,8 & 3,8 & 2,5 & 3,2 & 3,0 & 3,2 \\
\hline Brasil & 8,0 & 6,9 & 6,1 & 5,1 & 5,2 & 4,2 & 4,1 & -- & 3,9 & 3,3 \\
\hline Equador & 9,9 & 8,7 & 7,8 & 5,2 & 5,8 & 5,4 & 5,2 & 4,1 & 3,6 & 3,4 \\
\hline Colômbia & 8,3 & 7,5 & 6,6 & 9,4 & 7,5 & 7,2 & 6,2 & 5,1 & 4,3 & 4,7 \\
\hline Bolívia & -- & 9,5 & 14,8 & 12,8 & 10,3 & 8,6 & 8,5 & -- & 5,5 & 6,5 \\
\hline Chile & 1,6 & -- & -- & 1,0 & -- & -- & 1,1 & -- & 0,8 & -- \\
\hline Argentina & 7,6 & 5,3 & 3,9 & 3,1 & 2,8 & 2,4 & 2,3 & 1,6 & 1,3 & -- \\
\hline Guatemala & 13,5 & 13,0 & -- & 10,4 & -- & -- & -- & -- & 11,2 & -- \\
\hline Honduras & 19,7 & 18,8 & 20,5 & 17,3 & 12,4 & 11,3 & 9,6 & 10,5 & 13,2 & -- \\
\hline Nicarágua & -- & -- & 3,7 & -- & -- & -- & 7,2 & -- & -- & -- \\
\hline Venezuela & 15,9 & 13,6 & 11,3 & 5,9 & -- & -- & -- & -- & -- & -- \\
\hline
\end{tabular}

* Percentual de pessoas que vivem com até US\$2 por dia.

Fonte: Banco Mundial, 2003-2012

\section{Responsabilidade dos partidos e das elites para a qualidade da democracia na América Latina - notas finais.}

O combate à pobreza tem sido a bandeira maior de todos os governos recentes na América Latina, mesmo porque há constrangimentos internacionais por parte do Banco Mundial e da ONU para que isso ocorra. Para todos os países aqui examinados, os dados são positivos, ou seja, a queda da pobreza é efetiva. Provavelmente, pelos dados que vimos, esses avanços têm sido de grande valia para o fortalecimento de várias lideranças pessoais ou de partidos personalistas. $\mathrm{O}$ quadro abaixo, com informações até 2012, ainda que de forma incompleta, mostra com otimismo o panorama da pobreza nos 18 países examinados. De forma geral, os dados têm sido sustentáveis, com as exceções de Guatemala e Honduras. Os casos de sucesso mais surpreendentes são os de El Salvador, Argentina e Equador.
A fonte consultada não fornece dados completos para alguns países, entre eles, Venezuela e Nicarágua, sintomaticamente, os países pior avaliados em termos de democracia eleitoral.

Seguramente, o combate à fome e à pobreza foi o tema eleitoral mais importante nesses países, proposta muitas vezes revestida de um ideário anti-imperialista, socialista, antiliberal e antimercado. Na prática, todos esses países portaram-se do ponto de vista econômico dentro de parâmetros previstos pelas agências internacionais de fomento, praticaram políticas de exportação de commodities para o mercado internacional e não desenvolveram políticas industriais mais ousadas. As mudanças mais significativas vieram das políticas de transferência de renda que possibilitaram a $50 \%$ da população passar para a classe média em termos de consumo ${ }^{17}$. Este impactante manejo social deverá continuar a ter implicações importantes no campo da política, especialmente nas demandas por maior qualidade da democracia e pela melhoria dos serviços públicos e sociais.

Contudo, a fragilidade das instituições de segurança, contaminadas por falta de controle e por corporativismo, 
na maior parte dos países aqui citados, prejudica os sentimentos de segurança e de confiança do cidadão. Novas institucionalidades jurídicas surgiram no âmbito da redemocratização, mas ainda não são capazes de atender à demanda reprimida por direitos. A América Latina, repetimos, continua a ser o continente mais violento $\mathrm{e}$ mais desigual do mundo.

Ao longo deste trabalho, deixamos claro que há evidências de avanços inequívocos na democracia dos países aqui arrolados. Verifica-se também que os dados nem sempre são coerentes. Por exemplo, a presença da representação feminina não é maior nos países mais democráticos, vide os casos do Chile e do Brasil. E ainda, a satisfação com a democracia não é sempre maior entre os países que apresentam melhores indicadores de qualidade da democracia. Aqui, de novo, o caso do Chile é exemplar. Pode-se aludir também que aspectos legais e formais podem contribuir para a baixa ou alta qualidade da democracia, mas que há, também, características culturais que incentivam esses resultados. Uma delas é certamente o pouco valor atribuído à vida, especialmente a de negros, indígenas, jovens e mulheres. Da mesma forma, os precários cuidados educacionais e assistenciais com a infância sinalizam para uma trajetória pouco animadora em relação ao passado. Em meio a esses déficits, tão característicos da América Latina, os partidos políticos e as elites foram, e continuam sendo, mais agentes do status quo do que agentes da mudança.

\section{Referências}

ALCÁNTARA SAEZ, Manuel; FREIDENBERG, Flavia. Partidos políticos na América Latina. Opinião Pública, v. 8, n. 2, p. 137-157, 2002.

ALVES, José Eustáquio Diniz; PINTO, Céli Regina Jardim; JORDÃO, Fátima. As mulheres nas eleições de 2010. São Paulo: ABCP/Secretaria de Políticas para as Mulheres, 2012.

ARAÚJO, Clara. Partidos políticos e gênero: mediações nas rotas de ingresso das mulheres na representação política. Revista de Sociologia e Política, n. 24, p. 193-215, 2005.

BARREDA, Mikel. La calidad de la democracia. Un análisis comparado de América Latina. Política y Gobierno, Buenos Aires, v. 18, n. 2, p. 265-295, 2011.

CORRALES, Javier; PENDOLFI, Michael. Manipulating term limits in Latin America. Journal of Democracy, v. 25, n. 4, p. 157-168, 2014.

D'ARAUJO, Maria Celina. Militares, democracia e desenvolvimento: Brasil e América do Sul. Rio de Janeiro: Editora da FGV, 2010.

DUVERGER, Maurice. Os partidos políticos. Rio de Janeiro: Editora Guanabara, 1987.

GUGLIANO, Alfredo Alejandro. Apontamentos sobre o conceito de qualidade da democracia. Revista Debates (UFRGS), v. 7, p. 229-243, 2013.

HAGOPIAN, Francis. Derechos, representación y la creciente calidad de la democracia en Brasil y Chile. Política y Gobierno, v. 12, n. 1, p. 41-90, 2005.

LAMOUNIER, Bolívar. Representação política: a importância de certos formalismos. In LAMOUNIER, B.; WEFFORT, F.; BENEVIDES, M.V. (orgs.). Direito, cidadania e participação. São Paulo:T. A. Queiroz Editor, 1981.

LEVINE, Daniel; MOLINA, José Enrique. La calidad de la democracia en América Latina: una visión comparada. América Latina Hoy, n. 45, p. 17-46, 2007.

MANIN, Bernard. As metamorfoses do governo representati- vo. Revista Brasileira de Ciências Sociais, v. 10, n. 29, p. 5-34, 1995. MELO, Carlos Ranulfo. Partidos e migração partidária na Câmara dos Deputados. Dados, v. 43, n. 2, p. 207-239, 2000.

. The 2014 elections and the Brazilian party system. Brazilian Political Science Review, v. 9, n. 1, p. 93-114, 2015. MOISÉS, José Álvaro. O Congresso Nacional, os partidos políticos e o sistema de integridade: representação, participação e controle. Rio de Janeiro: Fundação Konrad Adenauer, 2014.

MORLINO, Leonardo. Changes for democracy. Actors, structures and processes. Oxford University Press: Oxford, 2011.

La calidad de las democracias en América Latina. Informe para IDEA Internacional. Estocolmo e San José: IDEA e LUISS, 2013.

O'DONNELL, Guillermo. Accountability horizontal e novas poliarquias. Lua Nova, n. 44, p. 27-54, 1998.

PÉREZ-LIÑÁN, Aníbal. A two-level theory of presidential instability. Latin American Politics and Society, v. 56, n. 1, p. 3454, 2014.

PION-BERLIN, David. Militares y democracia en el nuevo siglo. Nueva Sociedad, n. 213, p. 50-63, 2008.

PION-BERLIN, David; TRINKUNAS, Harold. Civilian praetorianism and military shirking during constitutional crises in Latin America. Comparative Politics, v. 7, n. 1, p. 395411, 2010.

SANTOS, Wanderley Guilherme dos. O buraco negro do PT. Segunda Opinião, 8 de maio de 2015.

SILVA, Fabricio Pereira da. Quinze anos da onda rosa latino-americana: balanço e perspectivas. Observador On-Line, v. 9, p. 1, 2014.

SKOCPOL, Theda; FIORINA, Morris P. (eds). Civic engagement in American democracy. Nova York: The Brooking Institution Press, 1999.

SOUZA, Maria do Carmo Campello. Estado e partidos políticos no Brasil (1930 a 1964). São Paulo:Alfa-Omega, 1976. 


\title{
Perspectives on democratic development and quality of democracy: Brazil and Latin America
}

\begin{abstract}
:
The paper presents a general picture of the state of democracy in Brazil and 17 other Latin American countries and is divided into two parts. At first, it shows that political democracy has achieved unprecedented levels in these countries and that substantial improvements in socioeconomic indicators are visible in almost all of them. It also explains that the emergence of personal leadership has a negative impact on democratic development indexes. In the second part, we focus on Brazil, which stands out also by positive data in the social issues and has approved a series of measures to improve electoral and government controls. The paper argues that the democratization and political liberalization process in these countries is real, but not always linear and progressive, and that the disregard for life and persistent structural inequality seem to demand new ways of thinking democratic practices in Latin America.
\end{abstract}

Key words: quality of democracy; Latin America; Brazil; inequalities; political parties.

\section{Perspectivas sobre desarrollo democrático y calidad de la democracia: Brasil y América Latina}

\section{Resumen:}

El artículo presenta un panorama general del estado de la democracia en Brasil y otros 17 países de América Latina y se divide en dos partes. En un primer momento, se demuestra que la democracia política ha alcanzado niveles sin precedentes en estos países y que las mejoras sustanciales en los indicadores socioeconómicos son visibles en casi todos ellos. También explicita-sé que el surgimiento de los liderazgos personales ha tenido impacto negativo en los índices de desarrollo democrático. En la segunda parte, nos centramos en Brasil, que se destaca también por los datos positivos en lo social y que ha aprobado una serie de medidas destinadas a mejorar los controles electorales y del gobierno. El artículo sostiene que el proceso de democratización y liberalización política en estos países es real, pero no siempre es lineal y progresivo, y que el desprecio por la vida y la persistente desigualdad estructural parece exigir nuevas formas de pensar las prácticas democráticas en América Latina.

Palabras clave: calidad de la democracia; América Latina; Brasil; desigualdades; partidos políticos. 
